\title{
Factors impact of energy consumption in Thailand's frozen seafood industry
}

\author{
Wongkot Wongsapai ${ }^{\mathrm{a},{ }^{*}, \text { Parida Malakrong }}{ }^{\mathrm{b}}$ and Tanapat Kanjananirin ${ }^{\mathrm{b}}$ \\ ${ }^{a}$ a Department of Mechanical Enginerring, Faculty of Engineering, Chiang Mai University, Chiang Mai, 50200 Thailand \\ ${ }^{b}$ Energy Technology for Environment Research Center, Chiang Mai University, Chiang Mai, 50200 Thailand
}

\begin{abstract}
The industrial sector, which has brought about a large demand for energy, totally consumed accounting for $37 \%$ of total energy consumption. This research accessed ten designated factories in Thailand's frozen seafood industry and evaluate the energy baseline for selected frozen raw shrimp and boiled shrimp products in Thailand based on energy data in 2016. This study focused on factor impacts of energy consumption by multiple regression method. The frozen products consist of raw frozen shrimp and boiled frozen shrimp frozen in IQF using direct contact and indirect contact. The result shows factors affecting energy consumption were freshwater production, ice production, working hour, waste water system, finished good management (only frozen raw shrimp or frozen boiled shrimp) and ambient temperature. The energy baseline of these factories have been developed.
\end{abstract}

Keywords: Specific energy consumption, Energy baseline, Energy efficiency, Frozen seafood energy, Thailand

\section{Introduction}

Thailand, as a developing country, is the second largest economy in Southeast Asia nation. It not only consumes an enormous energy but also releases a large amount of greenhouse gas, especially in the energy sector including the power sector, the transportation sector, the industrial sector, the commercial sector and the residential sector [1]. Thailand's energy and energy efficiency situation in 2016 from Department of Alternative Energy Development and Efficiency (DEDE), the total final energy consumption by economic sectors amounted to $79,929 \mathrm{ktoe}$, rising up $2.6 \%$ from the previous year. The industrial sector, which has brought about a large demand for energy, totally consumed about 27,951 ktoe, accounting for $37 \%$ of total energy consumption [2]. Thailand has long term plan for reduce total energy consumption namely Energy Efficiency Plan 2015 (EEP2015). Energy is an important input for providing the basic services of human needs, and is a key input to sustainable development and poverty reduction efforts. Thus, the role of energy is strongly linked to social, economic, and environmental development [3]. Freezing and frozen storage have been widely used to retain sensory quality and nutrients of seafood and their products. Some $50 \%$ of the total processed seafood consumed as well as $21 \%$ of total seafood production were offered to markets in the form of frozen products. [4] The frozen seafood industrial has been shared large amount of Thailand's GDP. It also has never been studied the baseline of energy consumption in this sector. Thus, this sector has potential to reduce energy consumption.

\section{Designated Factory}

\subsection{Background of frozen seafood}

There are 10 factories from frozen seafood industry in this study. The energy consumption pattern in

\footnotetext{
* Manuscript received July 14, 2018; revised March 4, 2019.

Corresponding author. Tel.: +66-81-81-2002; E-mail address: wongkot@eng.cmu.ac.th.

doi: $10.12720 /$ sgce.8.3.271-275
} 
frozen seafood industry is difference in the sector which there are the complicated manufacturing processes and various significant machines. There are various products such frozen raw shrimp, frozen boiled shrimp, frozen shrimp tempura, and shrimp fried rice. The analyze results show that the chiller system holds the most part of electrical energy as $57 \%$ and boiler takes almost as $97 \%$ of thermal energy presented in Fig 1.

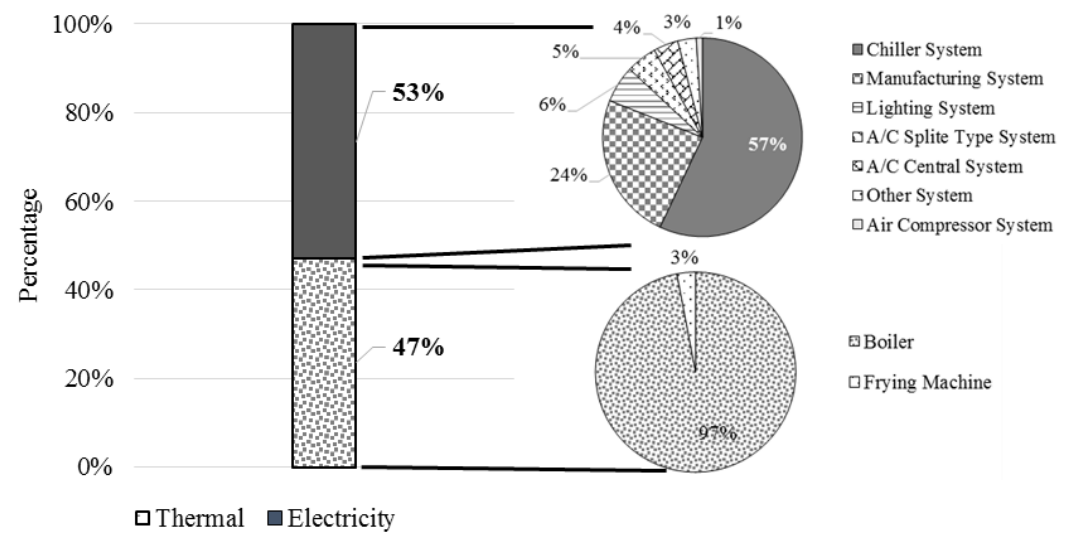

Fig. 1. Energy consumption pattern in frozen seafood industry.

\subsection{Process and Energy use in the frozen seafood industry}

Shrimp is rapidly spoiled by the active enzymes micro flora in its viscera and the spread yellowish liquid over its abdomen. Therefore, cooling is essential to keep wet shrimp in good condition. Generally, shrimp can be marketed chilled or frozen, peeled and cooked or canned. Freezing of shrimp is usually done at -25 to $-40{ }^{\circ} \mathrm{C}$ in quick freezers. Raw shrimp may be frozen in blocks or individually quick frozen (IQF) using contact plate or air blast spiral freezers. [5] This study frozen products include whole raw frozen shrimp and boiled frozen shrimp frozen in IQF using direct contact and indirect contact. The manufacturing process of frozen seafood presented in Fig 2.

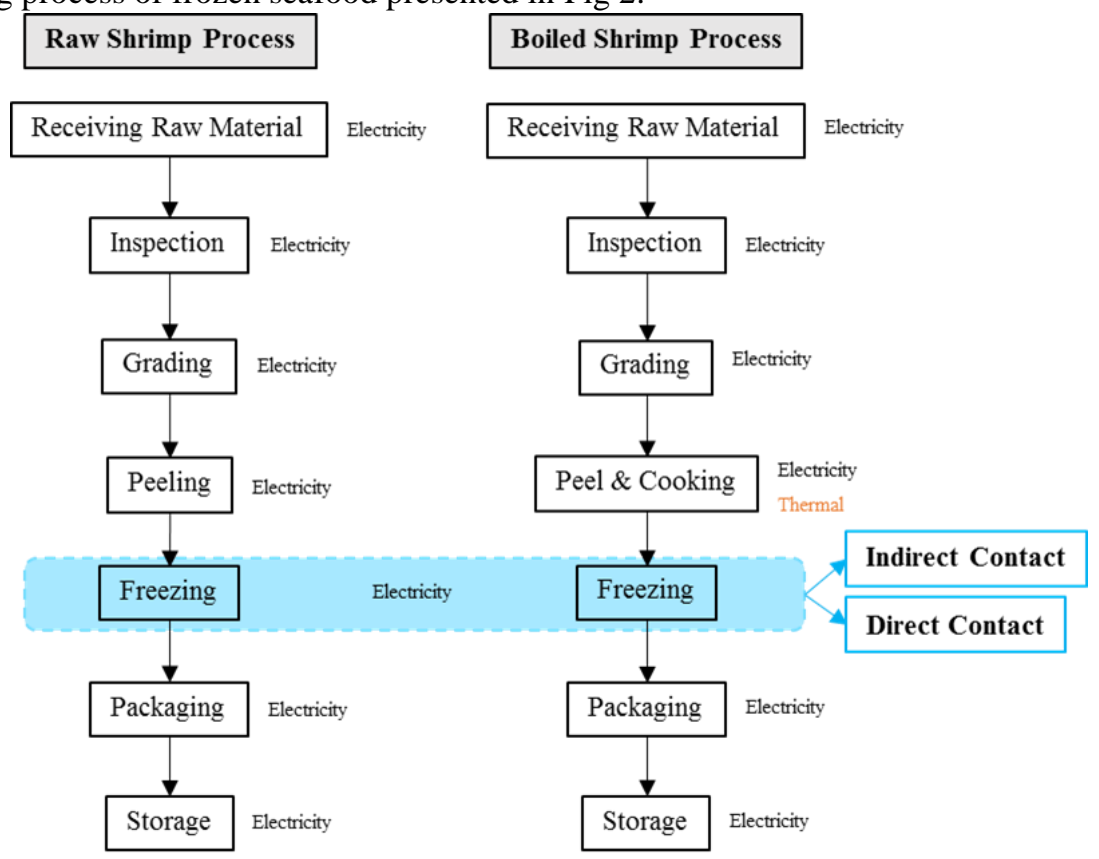

Fig. 2. Simplified diagram of frozen production that relates the main steps and forms of energy used 


\section{Methodology}

\subsection{Specific Energy Consumption (SEC)}

The Energy Utilization Index or Specific Energy Consumption (SEC) is determined by the total energy consumption of designated factory and product output is quantity of the product reference as Eq. (1)

$$
\mathrm{SEC}=\frac{\Sigma \text { Energy }}{\text { Product Output }}
$$

\subsection{Energy baseline}

Regression analysis is the mathematical statistics method treating the statistical correlation of the variables, with the basic thought to find the mathematical expression form representing the relationship between independent variable and dependent variable. The regression analysis with two or more independent variables is called multiple regression [6] reference as Eq. (2)

$$
\mathrm{Y}=\mathrm{b}_{0}+\mathrm{b}_{1}\left(\mathrm{X}_{1}\right)+\mathrm{b}_{2}\left(\mathrm{X}_{2}\right)+\mathrm{b}_{3}\left(\mathrm{X}_{3}\right)+\ldots+\mathrm{b}_{\mathrm{n}}\left(\mathrm{X}_{\mathrm{n}}\right)+\epsilon
$$

$\mathrm{b}_{0}, \mathrm{~b}_{1} \ldots \mathrm{b}_{\mathrm{n}}$ are the regression coefficients, and $\in$ is an error.

Developing suitable baseline energy models is essential to understanding current energy use and exploring energy-saving alternatives. [7] Actual consumption data record for 2016 from Thailand designated factory database. This data was divided into data set to be used in a multiple regression analysis to generate energy equation or energy baseline.

\section{Result}

There are 3 significant equipment such freezing, chiller, and boiler. Boiler technology: Fire tube boiler is widely used for all participants in frozen seafood industry. It is an original technology that consume more fuel whereas the new technology as Once-through boiler is better efficiency. Heat loss is less and generating efficiency high as $85-95 \%$. Though this technology has costly investment and short payback period. Freezing technology: For instance, Individual quick freezing: IQF by freezer. There are several freezing technologies such spiral freezer, belt freezer, fluidized bed freezer, cryogenic freezer using liquid $\mathrm{CO} 2$ (Direct Contact), and contract plate. They could not compare which one is the best because it depends upon manufacturing process of each factory. There are 2 groups into the potential evaluation in frozen seafood industry such frozen raw shrimp process and frozen boiled shrimp process. Frozen seafood normally use freezer in the freezing process. Comparison between the two type of freezing technology (Indirect Contact and Direct Contact) are showed as SEC with best practice (BPT) of frozen raw shrimp and boiled shrimp. The results indicated that the SEC of frozen raw shrimp and SEC of frozen boiled shrimp by direct contact lower than for indirect contact. This study shows the results in Table 1.

Table 1. SEC with best practice (MJ/ton).

\begin{tabular}{lll}
\cline { 2 - 3 } Product & SEC (MJ/ton) & \\
\cline { 2 - 3 } & Indirect contact & Direct contact \\
\hline Raw shrimp & 2,330 & $2,074^{*}$ \\
Boiled shrimp & 9,653 & $6,979^{*}$ \\
\hline
\end{tabular}

* Best practice (BPT)

Multiple regression attempts to model the relationship between two or more explanatory variables, value of the independent variable $\mathrm{X}$ is associated with a value of the dependent variable $\mathrm{Y}$. The energy data would be applied by multiple regression method to analyze factors, which impact the energy consumption of sector. The factors that impact of energy presented in Table 2 and Table 3. 
Table 2. Dependent Variables (Y).

\begin{tabular}{lll}
\hline Factor & Description & Unit \\
\hline Y1 & Electrical energy consumption: raw shrimp (indirect contact) & MJ \\
Y2 & Total energy consumption: boiled shrimp (indirect contact) & MJ \\
Y3 & Electrical energy consumption raw shrimp (direct contact) & MJ \\
Y4 & Total energy consumption: boiled shrimp (direct contact) & MJ \\
\hline
\end{tabular}

Table 3. Explanatory/Independent Variables (X).

\begin{tabular}{lll}
\hline Factor & Description & Unit \\
\hline X1 & Raw material input in process & $\mathrm{kg}$ \\
X2 & Freshwater production & $\mathrm{m} 3$ \\
X3 & Ice production & $\mathrm{kg}$ \\
X4 & Working Hour & $\mathrm{hr}$ \\
X5 & Peeled shrimp shell & $\mathrm{kg}$ \\
X6 & Waste water system & $\mathrm{m} 3$ \\
X7 & Number of worker & $\mathrm{Man}$ \\
X8 & Finished good (only frozen raw shrimp or frozen boiled shrimp) & $\mathrm{kg}$ \\
X9 & Finished good (all product) & $\mathrm{kg}$ \\
$\mathrm{X}_{10}$ & Ambient temperature & ${ }^{\circ} \mathrm{C}$ \\
\hline
\end{tabular}

The final regression equations of frozen seafood sector are calculated:

$$
\begin{aligned}
& Y_{1}=0.006\left(X_{4}^{2}\right)-4.175 \times 10^{-6}\left(X_{8}^{2}\right)+1.716 \times 10^{-6}\left(X_{9}^{2}\right)-12,694.159\left(X_{10}^{2}\right) \\
& -5.556 \times 10^{-12}\left(X_{4} X_{8} X_{9} X_{10}\right)-71.696 X_{4}+8.241 X_{8}-3.992 X_{9} \\
& +676,144.111 X_{10}-7,996,732.723
\end{aligned}
$$

Reference as Eq. (3) with parameters of quality analysis as $R^{2}=0.953$

$$
\begin{aligned}
& Y_{2}=-1.549 \times 10^{-5}\left(X_{8}^{2}\right)-1,954.606\left(X_{10}^{2}\right)+1.32\left(X_{8} X_{10}\right)-17.136 X_{8} \\
& +94,739.863 X_{10}-1,207,579.997
\end{aligned}
$$

Reference as Eq. (4) with parameters of quality analysis as R2 $=0.974$

$$
\begin{aligned}
& Y_{3}=-0.011\left(X_{6}^{2}\right)+9.89 \times 10^{-7}\left(X_{8}^{2}\right)-6.911 \times 10^{-7}\left(X_{9}^{2}\right)-4,268.692\left(X_{10}^{2}\right) \\
& +6.131 \times 10^{-12}\left(X_{6} X_{8} X_{9} X_{10}\right)+101.237 X_{6}+1.034 X_{8}+0.308 X_{9} \\
& +244,198.315 X_{10}-2,947,762.231
\end{aligned}
$$

Reference as Eq. (5) with parameters of quality analysis as R2 $=0.870$

$$
\mathrm{Y}_{4}=97.228 \mathrm{X}_{2}-0.704 \mathrm{X}_{3}+33.93 \mathrm{X}_{6}+2.327 \mathrm{X}_{8}+360,489.251
$$

Reference as Eq. (6) with parameters of quality analysis as R2 $=0.987$

\section{Conclusion}

The aim of the present study was to evaluate energy baseline in the frozen seafood sector for selected frozen raw shrimp and boiled shrimp products in Thailand in 2016 by multiple regression. Energy baseline of frozen shrimp differed according to the type of product, processing method IQF frozen (Indirect Contact and Direct Contact). In conformity with the equation presenting the factors affecting the energy consumption, the factors were freshwater production (X2), ice production (X3), working hour (X4), waste water system (X6), finished good (X8), finished goods for all products (X9) and ambient temperature $(\mathrm{X} 10)$. In addition, the influence of factors depends on value $\mathrm{X}$ in equation. 


\section{References}

[1] Atchariya C, Pornpimol W, and Bundit L. Assessment of renewable energy and energy efficiency plans in Thailand's Industrial Sector. Energy Procedia, 2017; 138: 841-846.

[2] Department of Alternative Energy Development and Efficiency, Ministry of Energy. (2016). Thailand Energy Efficiency Situation 2016 Bangkok: Department of Alternative Energy Development and Efficiency, Ministry of Energy

[3] Parida M, Wongkot W, Det D. Analysis of energy utilization index in Thailand sanitary ceramics sector. Energy Procedia 141 (2017): 170-174.

[4] Mehdi N, Soottawat B, Kaveh R. Hydrolysates from marine sources as cryoprotective substances in seafoods and seafood products. Trends in Food Science \& Technology, 2016; 57: 40-51.

[5] Nadia A. Abd-El-Aziz, Moharram YG. Microbiological quality of imported frozen shrimp in Egypt. Annals of Agricultural Science, 2016; 61(1): 35-40.

[6] Nian Y, Zhen L, Yuan F. Empirical study for influencing factors on environmental accounting information disclosure in chemical industry. Chemical Engineering Transactions 62 (2017): 1591-1596.

[7] Allyson G, Keith W, Joseph C and Zheng O. Change point and degree day baseline regression models in industrial facilities." Energy and Buildings 144 (2017): 30-41. 